\title{
PERCURSOS FORMATIVOS E EXPERIÊNCIAS INTEGRADORAS NO ENSINO SUPERIOR: PARTILHAS NO BRASIL E EM PORTUGAL
}

\author{
CAMINOS FORMATIVOS Y EXPERIENCIAS INTEGRADORAS EN LA \\ ENSEÑANZA SUPERIOR: REPARTES EN BRASIL Y PORTUGAL
}

\author{
TRAINING COURSES AND INTEGRATIVE EXPERIENCES IN HIGHER \\ EDUCATION: SHARES IN BRAZIL AND PORTUGAL
}

\author{
Adriana Rocha BRUNO ${ }^{1}$ \\ Cristhiane Carneiro Cunha FLOR ${ }^{2}$
}

\begin{abstract}
RESUMO: No século XX diversos movimentos focalizaram a formação de professores em suas múltiplas possibilidades e o século XXI, como herança, precisa superar muitos desafios, dentre eles a formação dos docentes no/do Ensino Superior. A educação superior brasileira e portuguesa recebem professores formados, prioritariamente, para atuação em pesquisa, e submetem-se aos modelos alemão e norte-americano que alicerçam os cursos de pós-graduação stricto sensu, pautando-se na cisão entre ensino e pesquisa. $\mathrm{O}$ presente artigo trata dos processos formativos para a docência no Ensino Superior nos contextos brasileiro e português, a partir do olhar para duas pesquisas realizadas: a primeira retrata as ações desenvolvidas na implantação de um Programa de formação docente para professores ingressantes numa universidade pública brasileira e a segunda investigação traz dados de uma pesquisa desenvolvida em três universidades portuguesas sobre ações institucionais voltadas à docência no Ensino Superior. No primeiro caso, o estudo aponta que os professores consideram a formação continuada proveitosa, sugerindo continuidade, embora questionem a obrigatoriedade e algumas atividades realizadas à distância. No segundo, evidenciam-se a ausência de um Programa institucional e a capilaridade das ações formativas, trazendo algumas inovações; a não obrigatoriedade e seus desdobramentos e a carência de formação para a cultura digital.
\end{abstract}

PALAVRAS-CHAVE: Formação docente no Ensino Superior. Percursos formativos. Experiências integradoras.

\footnotetext{
${ }^{1}$ Pós-doutora em Educação pelo Instituto de Educação da Universidade de Lisboa-PT, Doutora e Mestre em Educação: Curriculo pela PUCSP e licenciada em Pedagogia. É professora Adjunta do Depto. de Educação, da Universidade Federal de Juiz de Fora (UFJF), professora dos Programas de Pós-Graduação em Educação e em Gestão e Avaliação da Educação Pública - ambos da UFJF. E-mail: arbruno@gmail.com.

${ }^{2}$ Doutorado em Educação Científica e Tecnológia pela UFSC (2009). Faz parte do grupo Discursos da Ciência e Tecnologia (DICITE) na mesma instituição, e do Nucleo de Educação em Ciência, Matemática e Tecnologia (NEC) da Faculdade de Educação na UFJF, sendo ambos vinculados ao CNPQ. Foi professora de química no ensino médio na rede de educação do Estado de Santa Catarina, professora substituta no Departamento de Metodologia de Ensino da UFSC, professora Adjunta no Departamento de Química da Universidade Federal de Viçosa e atualmente é professora adjunta na Faculdade de Educação e no PPGE da Universidade Federal de Juiz de Fora. Coordena o Grupo de Pesquisa Co(m)textos cadastrado no CNPq. E-mail: cristhianeflor@yahoo.com.br.
} 
RESUMEN: En el siglo XX diferentes movimientos miraran hacía la formación de profesores en sus múltiples posibilidades y en el siglo XXI, como herencia, se necesita superar muchos desafíos, por ejemplo, la formación docente en/de la Enseñanza Superior. La educación superior brasileña y portuguesa recibe profesores formados, de manera prioritaria, para actuar en la investigación, que están basados en los modelos alemanes y estadunidenses que constituyen los cursos de pos-grado strictu sensu, pautados en la ruptura entre la enseñanza y la investigación. El presente artículo discute los procesos formativos para la docencia en la Enseñanza Superior en los contextos brasileño y portugués, a partir de la mirada hacía dos investigaciones realizadas: la primera presenta las acciones desarrolladas en la implantación de un Programa de formación docente para profesores ingresantes en una universidad pública brasileña y la segunda aporta datos de una investigación llevada a cabo en tres universidades portuguesas sobre las acciones institucionales para la docencia en la Enseñanza Superior. En el primer caso, el estudio muestra que los profesores consideran la formación continuada importante, sugiriendo continuidad, aunque cuestionan la obligatoriedad y algunas actividades realizadas a distancia. En el segundo, evidencian la ausencia de un Programa institucional y la capilaridad de las acciones formativas, presentando algunas innovaciones; la no obligatoriedad y sus desdoblamientos y la carencia de la formación para la cultura digital.

PALABRAS CLAVE: Formación docente en Enseñanza Superior. Caminos formativos. Experiencias integradoras.

ABSTRACT: In the twentieth century, several movements focused on the training of teachers in its multiple possibilities. The twenty-first century must overcome many challenges, including the training of teachers of Higher Education. The Brazilian and Portuguese higher education get trained teachers primarily for research activities. They submit to the German and US models that underpin the post-graduate studies courses, basing on the split between teaching and research. This article deals with the formative processes for teaching in higher education in the Brazilian and Portuguese contexts, from looking at two studies carried out: the first one portrays the actions undertaken in the implementation of a teacher training program for teachers entering a Brazilian public university and the second brings research data from a survey conducted in three Portuguese universities on institutional actions aimed at teaching in higher education. In the first case, the study shows that teachers consider useful continuing education, suggesting continuity, although question the obligation and some activities in the distance. In the second case, evidence of the absence of an institutional program and outreach of training activities, bringing some innovations; not mandatory and its consequences and the lack of training for digital culture.

KEYWORDS: Teacher training in Higher Education. Training Courses. Integrative experiences. 


\section{A Formação de Professores para o Ensino Superior no Brasil}

Ao pensar a formação de pós-graduandos, é possível perceber que os modelos alemão e norte americano sustentaram as bases dos cursos de pós-graduação stricto sensu brasileiros. O investimento e fortalecimento da pesquisa é, sem dúvidas, responsável por tantas mudanças e conquistas tanto no Brasil quanto no mundo. A pesquisa tem ajudado a transformar significativamente diversos campos do conhecimento e, no caso da Educação e formação de professores é evidente o quanto avançamos nas últimas décadas do século XX e neste um quarto do século XXI. Foi necessária imersão profunda em pesquisa para que pudéssemos amadurecer, formar pesquisadores e abrir campos de investigação e temas articulados com diferentes e complexas áreas do conhecimento. É chegado o momento, porém, de direcionarmos investimentos para um segmento que tem deixado lacunas e prejudicado, inclusive, a pesquisa: a formação de professores no/para/com o Ensino Superior. Se por um lado avançamos muito em pesquisa, por outro deixamos de lado o ensino e, ainda, como alertam Pimenta e Anastaciou (2002), separamos pesquisa de ensino "deixando à graduação a responsabilidade de formação dos quadros profissionais [...] e destinando à pós-graduação a responsabilidade da pesquisa" (Idem, p. 152).

Os cursos de pós-graduação, além de formarem pesquisadores, são os 'certificadores' da docência universitária. É por meio dos programas Stricto Sensu, em áreas diversas de licenciaturas e área de humanas, que se atesta a formação de professores, ainda que a maioria destes programas não desenvolva intencionalmente esta formação. Pensemos, por exemplo, num profissional que tenha cursado medicina e depois tenha feito mestrado e doutorado em cardiologia. Ao longo de sua formação muito provavelmente não houve sequer uma disciplina voltada para a docência no Ensino Superior. Mas, com esta formação ele estará certificado para o ingresso como docente em uma universidade no campo de seus estudos e pesquisas.

O fato é que persistimos na crença equivocada de que quem conhece (o conteúdo e/ou exerce a profissão) sabe (ou pode) ensinar! Trata-se de um equívoco comum e grandioso, pois do mesmo modo que é preciso aprender a medicina para ser médico, é preciso aprender a ser professor e isso não se faz com apropriação de conteúdo de áreas específicas, desconsiderando os estudos do campo da Educação. 
A formação para a docência universitária no Brasil tem se configurado em um cenário frágil, que gesta profissionais com lacunas na ação de ensinar. A seu turno, as instituições de ensino superior têm assumido com maior intensidade tais problemas, especialmente a partir da expansão de vagas docentes nas instituições públicas, com o Programa de Apoio a Planos de Reestruturação e Expansão das Universidades Federais (REUNI) - instituído pelo Decreto n 6.096 (BRASIL, 2007), uma das ações do Plano de Desenvolvimento Nacional (PDE).

A educação básica tem sido alvo de investimento público na formação de docentes ao longo das últimas décadas e isso deve ser ampliado cada vez mais. Destarte, a educação superior tem sofrido de uma carência significativa na formação para a docência dos que integram os quadros de professores universitários e este não é um retrato somente brasileiro, já que a carência nesta área também é identificada em outros países, como veremos adiante.

\section{Em Busca de Ações Formativas: O Caso da UFJF}

Afinada com as demandas formativas, a Universidade Federal de Juiz de Fora (UFJF) criou em 2011 a Coordenação de Inovação Acadêmica e Pedagógica do Ensino Superior - CIAPES junto à Pro Reitoria de Graduação - PROGRAD, cujo desafio inicial foi desenvolver ações formativas para a docência na educação superior, destinadas aos professores da instituição. Tais ações foram alicerçadas na compreensão e em propostas que implicam nos múltiplos letramentos necessários para a docência nos tempos atuais.

Respaldada pela Lei 12.772/2012, que dispõe, entre outros, sobre a Carreira do Magistério Superior e que estabelece, em seu inciso V do Art. 24 que o docente em estágio probatório deverá participar do Programa de Recepção de Docentes instituído pela Instituição Federal de Ensino, a UFJF formalizou uma proposta de formação. Foram emitidas as Portarias no. 04/PROGRAD, de 30 de setembro de 2013 e 02/PROGRAD, de 12 de fevereiro de 2014, que estabeleceram que o docente em Estágio Probatório precisa cumprir 120 horas de atividades formativas ao longo do período de três anos do estágio. Nesse contexto, coordenada pelas autoras deste artigo, a CIAPES desenvolveu, no período de 2012 a 2014, ações formativas para a docência em 
nível superior, direcionadas aos professores ingressantes da UFJF e, em 2012, foi criado o Programa Percursos Formativos para a docência no Ensino Superior.

No período de maio de 2012 a março de 2013, foi realizado um Projeto Piloto, que contou com a participação e colaboração de docentes da UFJF (Farmácia, Enfermagem, Engenharias, Institutos de: Artes e Design, Biológicas, Exatas, Humanas Letras, Educação, Economia, Odontologia, Medicina, Direito e Serviço Social). Tal fato foi fundamental para o planejamento de um programa de ações formativas que atendesse às demandas dos professores da UFJF. Optou-se por trabalhar junto a professores ingressantes no ano de 2011, na compreensão de que haveria convergência com a atuação destes como parceiros do Projeto Piloto, a saber: 1) possuírem mais tempo disponível para dedicação às ações propostas, pois, por terem ingressado recentemente, ainda não estariam totalmente consumidos pelas demandas da Universidade e da vida acadêmica; 2) apresentarem um olhar exotópico, no sentido bakhtiniano, e ideias potencializadoras e oxigenadas por quem está iniciando um trabalho em uma nova instituição. O convite foi endereçado a 94 docentes e, destes, 74 concluíram as atividades.

Após o piloto, no período de junho de 2013 a fevereiro de 2014, foram realizadas ações com o intuito de verificar as demandas apontadas, organizar os cursos, mobilizar os recursos humanos e financeiros, verificar a parte burocrática e logística etc, visando a primeira leva de ações formativas proporcionadas pela CIAPES. Tendo como princípios a autonomia e liberdade de escolha dos docentes ao formato e tema que mais se aproximasse de suas necessidades e possibilidades, foram propostas atividades na modalidade presencial e a distância, ancoradas na ideia de Educação Híbrida (BRUNO, 2012). Com ações fundamentadas na Educação Aberta, a Educação Híbrida traz, dentre outros aspectos, a integração dos espaços, encontros e atividades presenciais e online contando com a mediação das Tecnologias de Informação e Comunicação (TIC). Este tipo de educação tem se ajustado às demandas apresentadas pelos docentes, pois atende às subjetividades e especificidades do contexto dos professores da Universidade.

Na primeira etapa do Programa, ocorrida nesse período, foram oferecidos dois cursos: “Tecnologias da Informação e comunicação no Ensino Superior - TIC-ES (60h)" e "Docência no Ensino Superior (40h)". Também foram oferecidos cinco minicursos/oficinas: "Videoaulas: do roteiro á disponibilização (16h)", "Produção de audiovisual na educação (15h)", "Projeto de formação de professores através de ferramentas de som e produção de podcasts (20h)", "Projeto de material didático - 
módulo de contextualização (24h)", "CTS: um olhar sobre conhecimento e condição humana (25h)". Juntos, cursos, minicursos e oficinas somaram 310 vagas.

Na segunda etapa, ocorrida nos meses de fevereiro e março de 2014, foram oferecidos seis cursos: “Tecnologias da Informação e comunicação no Ensino Superior - TIC-ES (20h)" e "Docência no Ensino Superior (35h)", "Estudo de Caso e outras estratégias práticas para o ensino superior (20h)", "Fundamentos teóricos da avaliação: refletindo sobre a prática (novo, 15h)", "TIC - Moodle I" (20h), "TIC - Moodle II" (20h) . Também foram oferecidas 06 oficinas, a saber: "Podcast e recursos audiovisuais (20h)", "Imagens e narrativas: 'desconfiar das imagens', Harun Farock (novo, 25h)”, "Plágio e direito autoral na docência no ensino superior (20h )", "Projeto de material didático - módulo de contextualização (24h)", "Utilização de artes e outros meios de apoio para o processo de ensino aprendizagem (10h)". No total, entre cursos e oficinas, foram abertas 300 vagas.

Participaram da primeira etapa 269 docentes e da segunda etapa 229 docentes da UFJF que estavam em estágio probatório. Dependendo do período do Estágio probatório no qual se encontrava, o docente participou de uma ou mais atividades do Programa, a fim de completar, ao todo, 120 horas de formação. Ao final de cada etapa foi proposto a todos os participantes que respondessem a um questionário avaliativo.

\section{Percursos Formativos na Visão dos Docentes da UFJF}

Após as duas etapas do Programa serem executadas, os questionários respondidos foram analisados, no intuito de compreender a visão dos docentes a respeito das ações formativas propostas. Os dados dos questionários foram tabulados e foram elaborados gráficos com as respostas a cada uma das 8 questões objetivas propostas. Cada questão foi respondida por meio de uma escala Likert (Ótimo, Bom, Sem elementos para avaliar, Ruim, Regular). Além da parte objetiva, as questões traziam um espaço para os comentários que os docentes julgassem relevantes.

Os docentes foram questionados sobre:

- $\quad$ Como avaliaram os encontros presenciais.

- $\quad$ Como avaliaram a organização geral da atividade da qual participou.

- $\quad$ Como avaliaram a proposta da atividade. 
- $\quad$ Como avaliaram a dinâmica utilizada para os cursos.

- $\quad$ Como avaliaram os materiais disponibilizados.

- $\quad$ Como avaliaram o atendimento da equipe CIAPES (coordenação e secretaria).

- $\quad$ Como avaliaram o atendimento da equipe CIAPES (professores e tutores).

- $\quad$ Como avaliaram o atendimento on-line.

Por razões de síntese, apresentaremos aqui apenas alguns dados qualitativos acerca dos comentários dos professores às questões referentes aos cursos, minicursos e oficinas. Maiores aprofundamentos serão apresentados em trabalhos futuros.

Com relação aos cursos, formato, proposta, dinâmica utilizada, os docentes acharam muito proveitosos, sendo os encontros presenciais considerados essenciais para a integração entre professores de diferentes áreas e também entre professores em início de carreira. Essas considerações vão ao encontro das questões apontadas no início do texto, que trazem a cisão entre ensino e pesquisa e também entre as diferentes áreas dentro de uma mesma Universidade. Os professores que estão iniciando sua atuação no ensino superior têm vontade e necessidade de se conhecer e trocar experiências. Nesse sentido, o Programa Percursos Formativos auxiliou propiciando o encontro entre diferentes sujeitos. Nas palavras dos professores Pedro, Jaque e Ana (nomes fictícios):

Pedro: Os encontros serviram para descobrir que possuímos preocupações comuns e para trocar ideias de soluções. Creio que foi bastante positivo.

Jaque: Muito importante a proposta uma vez que pôde reunir diversos professores de diferentes áreas, cada qual colocando o seu ponto de vista de acordo com sua atuação profissional.

Ana: Abriu muitos os meus horizontes no sentido de discutir o que é ser professor e qual o nosso papel na sala de aula.

Apesar de a maioria dos professores avaliarem bem a proposta, alguns apontaram críticas e dificuldades, como redundância da temática para sua área específica, especificidade da linguagem "pedagógica” e dificuldade no gerenciamento do tempo para a execução das atividades. É importante ressaltar que todos esses professores participaram de formação em serviço, sem haver dispensa ou diminuição de carga horária para cursarem as atividades. Isso faz pensar o lugar da formação do professor de ensino superior. Se essa não ocorre na pós-graduação, muitas vezes isso vai 
impactar no início da carreira docente, intensificando a carga de trabalho desse momento. Esse fator, ligado à obrigatoriedade de participação dos docentes em estágio probatório, gerou em alguns uma sensação de descontentamento, como pode ser visto nas falas de Joel, Marta e Dani (nomes fictícios):

Joel: Penso que o período de oferecimento dos cursos e oficinas poderia ser mais próximo do início dos semestres letivos para que possamos participar com mais tranquilidade.

Marta: É a primeira vez que faço um curso a distância, apesar da falta de tempo pra me adaptar ao horário, achei muito proveitoso

Dani: Sugiro que estes cursos se não sejam algo imposto para os professores em probatório.

De maneira geral, a proposta do Programa Percursos Formativos foi bem aceita e muito elogiada pelos docentes que participaram das formações, que destacaram, além dos pontos já mencionados, a importância da formação para a docência no ensino superior, o aprendizado de novas temáticas e práticas a serem desenvolvidas com os estudantes e o aprendizado proporcionado por participar de atividades, e mesmo cursos inteiros, realizados à distância ou de forma semipresencial. Alguns docentes, como no caso de Maria, Vânia e Roberto (nomes fictícios) sugeriram a continuidade e ampliação das ações da CIAPES:

Maria: Disponibilizar para todos os professores - Sugiro que continuem com estes cursos, futuramente expandindo para outros professores da nossa instituição que tiverem interesse. Parabenizo a equipe pela organização dos cursos.

Vânia: Sugiro módulos complementares e ações continuadas em próximas oportunidades.

Roberto: A proposta é válida e poderia ser de formação continua, dado que existem departamentos (acho que a maioria) que apenas reúnem os docentes para discussões administrativas e não pedagógicas.

Ao propor o Programa Percursos Formativos, apostamos na autonomia profissional, na formação para a docência e nas Tecnologias de Informação e Comunicação como forma de propiciá-las. Apesar do caráter obrigatório aos docentes em estágio probatório, a maioria dos participantes aprovou a proposta. Mesmo aqueles que questionaram a obrigatoriedade aprovaram o formato e as temáticas trabalhadas, 
mostrando que esse é um campo ainda carente de realizações e incentivando a continuidade do programa.

\section{Ações Formativas em Portugal: Três Universidades Lisboetas em Destaque}

A partir das experiências produzidas no Brasil, por meio da CIAPES-UFJF, e também após uma investigação concluída em 2015 e financiada pela FAPEMIG (BRUNO, 2015) em que foi possível conhecer um pouco das ações empreendidas por outras universidades nacionais, emergiu fortemente a necessidade de buscar outros processos formativos, construções cocriadas em contextos e cenários diversos, além mar. Assim, atendendo os chamados de investigações em terras estrangeiras, Adriana Bruno migrou para a Universidade de Lisboa para realizar o pós-doutoramento no Instituto de Educação, na linha de Formação de Professores, daquela instituição, com financiamento da CAPES.

Apoiada pela supervisão da Prof. Dra. Manuela Esteves, o pós-doutorado foi realizado com o objetivo de

\footnotetext{
investigar como as universidades públicas portuguesas de Lisboa tem desenvolvido, institucionalmente, a formação continuada de professores no/para o Ensino Superior, considerando as demandas atuais que suscitam a integração de áreas/conhecimentos, de saberes e de processos de aprendizagem, mediados por uma cultura digital. (BRUNO, 2015, p. 07)
}

Destacamos que o professor é percebido por nós como um sujeito emocional que afeta e é afetado pelas experiências emergentes. Não poderíamos então pensar simplesmente em docência, mas pluralizar este processo como docências.

Ainda que formação de professores tenha terminado o século XX com foco na questão política, sabe-se que este processo de desenvolvimento e aprendizagem humano abarca também o currículo, a aprendizagem etc. Se hoje temos mais clareza sobre a potencialidade e amplitude que envolvem o docente e a docência, e ainda, que adentramos o século XXI - com mudanças iniciada no anterior - com recursos, ideias, processos híbridos em meio à cultura digital que altera as relações entre humanos e com o conhecimento (isso apenas para sinalizar este momento revolucionário e transformador) a formação docente não pode estagnar. É fulcral que tais processos 
formativos se pluralizarem. Por isso que as docências no Ensino Superior assumem dimensão rizomática e plástica.

Os encontros do pesquisador com o campo de investigação e com seus intercessores/ interlocutores são potenciais para a aprendizagem integradora (BRUNO, 2007) e fomentam experimentos sobre o dito, o lido, o ouvido, o estudado e o debatido. Ao compactuar com os ensinamentos de Jorge Larrosa Bondía (2002), no que tange à experiência como divergente de experimento, em que a primeira se traduz por sua singularidade e o segundo pelas generalizações e repetições, evidencia-se o diálogo com Deleuze (1998), para quem estes processos são acontecimentos e, dito de outro modo, "Se a lógica do experimento produz acordo, consenso ou homogeneidade entre os sujeitos, a lógica da experiência produz diferença, heterogeneidade e pluralidade" (BONDÍA, 2002, p. 19).

Em consonância a estas premissas, o método assumido para as investigações apresentadas foi experienciar com os sujeitos envolvidos.

A multirreferencialidade, epistemologia proposta por Ardoino (1998) tem se apresentado como potente para compreender e assumir a mobilidade necessária no processo investigativo, tendo a possibilidade de uma pesquisa plural, múltipla. Tal opção se coaduna com as pesquisas produzidas e na compreensão de que (1) é o objeto ou sujeito que (m) sinaliza(m) a metodologia e, desse modo, a partir do objeto, do sujeito e do campo delineamos o método; e (2) a concepção de abertura do grupo se estende aos estudos e à filiação teórica; logo, buscamos múltiplas áreas que nos ajudem a compreender, experienciar e intervir no mundo contemporâneo.

A pesquisa em questão implicou três universidades públicas portuguesas, em Lisboa, e se deu por meio dos seguintes caminhos e instrumentos metodológicos:

a. levantamento bibliográfico no banco de dados da Universidade de Lisboa;

b. entrevistas semi-estruturadas com gestores, professores e técnicos implicados em ações formativas nas universidades investigadas;

c. questionário online destinados a gestores, professores e técnicos implicados em ações formativas em universidades portuguesas.

Para este artigo fizemos um recorte nos dados produzidos principalmente por meio das entrevistas com alguns pesquisadores e educadores cujos trabalhos e funções se integram às demandas desta investigação. 
Ao todo foram realizadas nove entrevistas: na Universidade de Lisboa foram entrevistados cinco profissionais entre docentes e técnicos; na Universidade Nova de Lisboa uma docente que é responsável por duas das frentes de formação continuada nesta instituição; e na Universidade Aberta de Portugal foram ouvidas duas professoras, responsáveis por um curso, online, de Formação para a Docência online e o Reitor desta Universidade. Os dados sinalizam que as universidades têm desenvolvido ações formativas para a docência no Ensino Superior para seus docentes e que tais ações são diversas. Ainda revelam ações formativas realizadas pelas universidades públicas portuguesas de Lisboa que merecem destaque por fomentarem as ideias e aspectos destacados como inovadores.

Cabe esclarecimento sobre inovação que, diferente de ineditismo, compreende ações praticadas pelos sujeitos de formas diferentes das até então realizadas. Não se trata de fazer ou produzir algo nunca feito, mas de incorporar práticas que podem ser conhecidas por outros em suas ações de docência. Neste sentido, é inovador para quem pratica/desenvolve.

Vamos às ações encontradas nesta investigação:

1. Projeto Observar e Aprender: inspirado nos "modelos anglo-saxónicos de Peer Observation and Review of Teaching e na sua adaptação portuguesa, o "De par em par" da Universidade do Porto (UP)"33 , esta proposta desenvolvida na Universidade de Lisboa, e sediada no Instituto Superior Técnico, integra docentes de disciplinas e áreas diferentes que, em grupos de quatro professores, assistem aulas uns dos outros, fazem observações a partir de um roteiro (guião ou grelha, como dito em Portugal) e trocam experiências sobre suas aulas e o que seria uma boa aula ou o que poderia ser melhorado e mantido em cada docência. Com o cuidado de integrar docentes de cursos diversos, esta proposta traz uma possibilidade de não focalizar os aspectos afeitos à docência ao tratamento exclusivo dos professores e estudiosos do campo da educação/pedagogia. Outro ponto importante é o de se abrir para ouvir e ser ouvido diante de demandas de suas docências, abrir sua aula para interferências de outros colegas e assumir-se como aprendiz e colaborador das docências alheias. Um ponto que intriga é a completa ausência, no guião, de um item que

${ }^{3}$ Disponível pelo site do Projeto Observar e Aprender: http://quc.tecnico.ulisboa.pt/observar-e-aprender/ 
trate dos recursos utilizados para o desenvolvimento das aulas e a relação da docência com os artefatos tecnológicos contemporâneos, muito presentes na vida de docentes e discentes, como elucidado pelos sujeitos.

2. Escola Doutoral: a inovação deste projeto está, principalmente, no fato de voltar ações formativas para doutorandos. Ainda que o objetivo direto de tais ações não sejam a docência - ou a formação para a docência - se os cursos de doutoramento conferem àqueles que se diplomam o título de docente do/no Ensino Superior é natural que neste processo formativo especializado sejam desenvolvidas ações que implicarão na docência daqueles que a exercerem. Neste ponto, criar uma Escola para tal processo reflete os movimentos contemporâneos, tão necessários aos processos formativos. Por outro lado, buscar formações amplas, não somente voltadas à docência num formato cartesianamente pedagógico, aufere aos processos formativos percursos mais dinâmicos e potentes para futuros docentes. Do mesmo modo, se estes processos forem abertos - em que os sujeitos livremente escolhem seus percursos/cursos tanto melhor, pois produz caminhos para a autonomia na docência e na profissão.

3. Formação para a docência online: este curso tem como foco a formação de professores para docência online. O diferencial deste curso é que ele é online, ou seja, não fala apenas sobre o processo online, mas por meio das experiências online desenvolve a formação online. Não foi possível ter acesso ao curso - não está disponível online e não foi possível avançar para além das entrevistas e dados produzidos por meio do questionário. Porém, os sujeitos relatam que diversas instituições portuguesas e estrangeiras têm procurado o curso e estimase que ofereça estrutura curricular implicada com a Didática online, mas não ficou claro se há processo de literacia digital crítica, para além da instrumental.

De modo muito similar ao desenvolvido pela CIAPES (UFJF) estes desenhos de formação criam, por percursos diversos e formatos múltiplos possibilidade formativas mais dinâmicas, autônomas, colaborativas e que ampliam o campo de visão de mundo destes profissionais. Por conseguinte, potencializam que se optarem pela docência, estes profissionais serão mais abertos ao novo e seus desdobramentos, essenciais a professores do ES. 


\section{Considerações Finais}

Propor ações formativas para docentes do ensino superior é um desafio

multifacetado, que sugere a necessidade de muitos e novos debates. É preciso, em primeiro lugar, pensar a necessidade de articular pesquisa e formação, de maneira que não formemos apenas pesquisadores ou apenas docentes, mas docentes que pesquisem inclusive sua própria prática. As experiências aqui relatadas, ocorridas em Juiz de Fora/Brasil e Lisboa/Portugal mostram que é possível caminhar nessa direção, incentivando a autonomia profissional, explorando as Tecnologias de Informação e Comunicação e levando em conta as demandas apresentadas por docentes em atuação.

\section{REFERÊNCIAS}

ARDOINO, J. Abordagem multirreferencial (plural) das situações educativas e formativas. In: BARBOSA, J. G. (coord.). Multirreferencialidade nas ciências e na educação. São Carlos: Editora da UFSCar, 1998.

BRASIL. DECRETO No 6.096, DE 24 DE ABRIL DE 2007. Disponível em: < http://www.planalto.gov.br/ccivil_03/_ato2007-2010/2007/decreto/d6096.htm>. Acesso em: 20 out. 2014.

BRUNO, A. R. A aprendizagem do educador: estratégias para a construção de uma didática on-line. Programa de Pós- Graduação em Educação: Currículo. 2007. 352 p. Tese de doutorado. Pontifícia Universidade Católica de São Paulo.

BRUNO, A. R. Ações formativas para educação online no Ensino Superior: a didática online e a aprendizagem do adulto em perspectiva. In: Yoshie Ussami Ferrari Leite, Alda Junqueira Marin, Selma Garrido Pimenta, Marineide de Oliveira Gomes, Aline Maria de Medeiros Rodrigues Reali. (Org.). Políticas de formação inicial e continuada de professores (E-BOOK). Araraquara-SP: Junqueira\&Marin Editores, 2012, v. 2.

BRUNO, A. R. Relatório Final de Pesquisa - FAPEMIG - Edital Universal (20132015), 2015.

BONDÍA, J. L. Notas sobre a experiência e o saber de experiência. Revista Brasileira de Educação. n. 19. Jan/fev/mar/abr, 2002. Disponível em: <http://www.anped.org.br/rbe/rbedigital/RBDE19/RBDE19_04_JORGE_LARROSA_B BONDIA.pdf $>$. Acesso em: 01 nov. 2014.

DELEUZE, G. Diferença e repetição. Trad. Luiz Orlandi e Roberto Machado. São Paulo: Graal, 1998. 
PIMENTA, S. G.; ANASTASIOU, L. G. C. Docência no Ensino Superior. São Paulo: Cortes, 2002.

\section{Como referenciar este artigo}

BRUNO, Adriana Rocha.; FLOR, Cristhiane Carneiro Cunha. Percursos formativos e experiências integradoras no ensino superior: partilhas no Brasil e em Portugal. Revista Ibero-Americana de Estudos em Educação, Araraquara/SP, v. 11, n. esp. 3, p.15731586, 2016. Disponível em: 〈http://dx.doi.org/10.21723/riaee.v11.n.esp3.9062〉. EISSN: 1982-5587.

Submetido em: agosto/2016

Aprovado em: novembro/2016 